\title{
Schizophrenia, CATCH 22 and FISH
}

\author{
KIERAN C. MURPHY and MICHAEL J. OWEN
}

Velo-cardio-facial syndrome (VCFS) is a syndrome of congenital abnormalities associated with small chromosomal deletions in the q11 band of chromosome 22. It was first reported by Strong in 1968 and further delineated by Shprintzen et al in 1978. Characteristic features include cleft lip and/or palate, hypernasal speech, congenital heart defects, learning disability and a distinctively long facial appearance with a bulbous nasal tip (Fig. 1). It has recently become apparent that VCFS is one of several overlapping phenotypes associated with deletions of 22q11 including DiGeorge syndrome, conotruncal anomaly face syndrome and sporadic or familial cardiac defects. The principal characteristics of these disorders have been summarised in the memorable acronym $\mathrm{CATCH} 22$ representing cardiac defects, abnormal facies, thymic hypoplasia, cleft lip and/or palate, hypocalcaemia and chromosome 22q11 deletions (Wilson et al, 1993).

These disorders are of interest to psychiatrists because VCFS appears to have a characteristic behavioural phenotype including a bland affect, monotonous voice, impaired attention and poor social interaction with extremes of disinhibited or shy behaviour (Golding-Kushner et al, 1985). Of even greater interest is that, as cohorts of VCFS patients have been followed-up into adult life, a significantly increased incidence of psychosis has been observed. Shprintzen et al (1992) reported that more than $10 \%$ of their sample of greater than 100 patients with VCFS developed psychiatric disorders, mostly "chronic schizophrenia with paranoid delusions". More recently, Pulver et al (1994) also found a higher than expected rate $(29 \%)$ of psychotic disorders (DSM-III-R schizophrenia or schizoaffective disorder; American Psychiatric Association, 1987) among VCFS patients with significantly higher rates of psychosis in second- and third-degree relatives.

This poses the interesting question of whether and to what extent $22 \mathrm{q} 11$ deletions are present in patients with schizophrenia.

Lindsay et al (1995) screened 100 unrelated patients and found chromosome 22q11 deletions in two patients. These results are interesting and provocative but clearly need replication and extension to larger samples.

This association with VCFS may have important implications for the aetiology of schizophrenia and suggests that $22 \mathrm{q} 11$ might contain a gene or genes of more general relevance to the disorder. It also suggests that clinicians should seek the clinical features of CATCH 22 in patients with schizophrenia or schizoaffective disorder. The presence of cleft lip and/or palate, characteristic dysmorph-

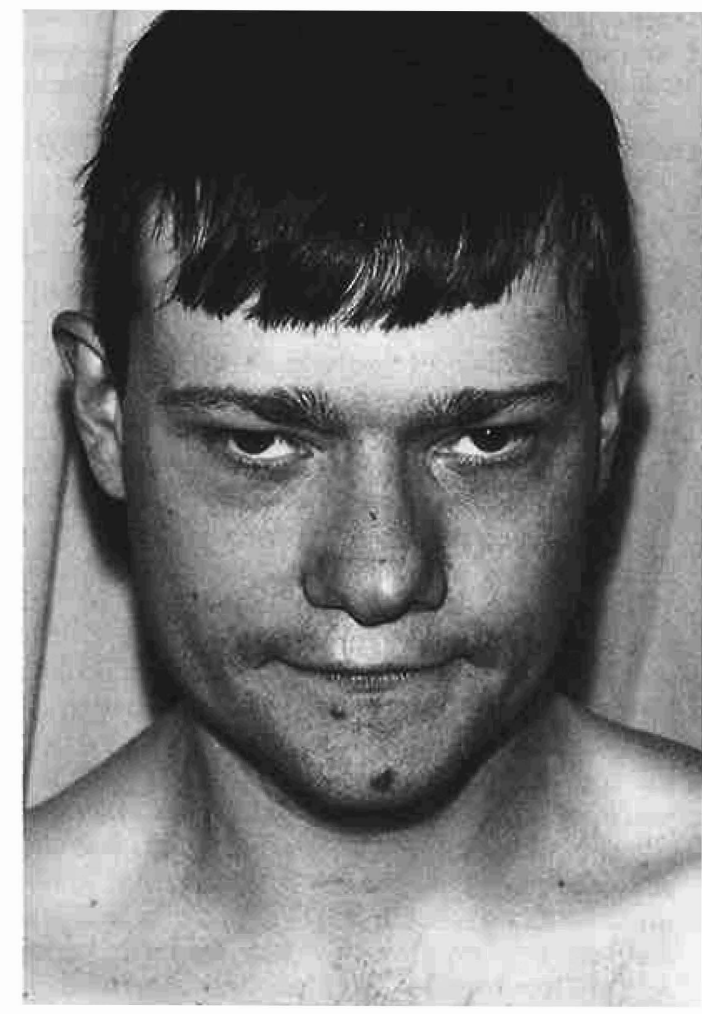

Fig. 1 Characteristic facial appearance in a patient with VCFS and DSM-III-R schizophrenia. 
ology (Fig. 1), learning disability, congenital heart disease or hypocalcaemia should raise the suspicion of a chromosome $22 \mathrm{q} 11$ deletion. In such cases, psychiatrists should request molecular cytogenetic studies of chromosome $22 \mathrm{q} 11$ using fluorescence in situ hybridisation (FISH). In those patients demonstrating a deletion, close liaison with the local Department of Medical Genetics is recommended to ensure that appropriate genetic counselling is provided.

\section{Acknowledgements}

This work was supported by the Medical Research Council and Glaxo Research and Development. We thank the family of the photographed patient for their cooperation.

\section{References}

American Psychiatric Association (1987) Diagnostic and Slatistical Manual of Mental Disorders (3rd edn, revised) (DSM-III-R). Washington, DC: APA.
Golding-Kushiner, K. J., Wet.ler, G. \& SHPrintzen, R. J. (1985) Velo-cardio-facial syndrome: Language and psychological profiles. Journal of Craniofacial Genetics and Developmental Biology, 5, 259-266.

Lindsay, E. A., Morris, M. A., Gos, A., et al (1995) Schizophrenia and chromosomal deletions within 22q11.2. American Journal of Human Genetics, 56, 1502-1503.

Pulver, A. E., Nestadt, G., Goldberg, R., et al (1994) Psychotic illness in patients diagnosed with velo-cardio-facial syndrome and their relatives. Joumal of Nervous and Mental Disease, 182, 476-478.

ShPrintzen, R. J., Gol.daerg, R. B., LEWIN, M. L., et al (1978) A new syndrome involving cleft palate, cardiac anomalies, typical facies and learning disabilities: velo-cardio-facial syndrome. Cleft Palate Journal, 15, 56-62.

the editor: Late-onset psychosis in the velo-cardio-facial syndrome. American Joumal of Medical Genetics, 42, 141-142.

Strong, W. B. (1968) Familial syndrome of right-sided aortic arch, mental deficiency, and facial dysmorphism. Journal of Pediatrics, 73, 882-888.

Wilson, D., Burn, J., Scambler, P., et al (1993) DiGeorge syndrome: part of CATCH 22. Journal of Medical Genetics, $\mathbf{3 0}$, 852-856.

Kieran Murphy, MRCPsych, Department of Psychological Medicine; Michael J. Owen, MRCPsych, Departments of Psychological Medicine and Medical Genetics, University of Wales College of Medicine, Cardiff CF4 $4 \mathrm{XN}$

Correspondence: Dr K. Murphy, MRCPsych, Department of Psychological Medicine, University of Wales College of Medicine, Heath Park, Cardiff CF4 4XN, Wales. Fax: 01222747839

(Received 26 October 1995, accepted 17 November 1995) 